\title{
No Evidence on Directional vs. Proximity Voting
}

\author{
Jeffrey B. Lewis \\ Princeton University \\ Gary King \\ Harvard University
}

\begin{abstract}
The directional and proximity models offer dramatically different theories for how voters make decisions and fundamentally divergent views of the supposed microfoundations on which vast bodies of literature in theoretical rational choice and empirical political behavior have been built. We demonstrate here that the empirical tests in the large and growing body of literature on this subject amount to theoretical debates about which statistical assumption is right. The key statistical assumptions have not been empirically tested and, indeed, turn out to be effectively untestable with existing methods and data. Unfortunately, these assumptions are also crucial since changing them leads to different conclusions about voter decision processes.
\end{abstract}

\section{Introduction}

Since Rabinowitz and Macdonald (1989) first proposed their "directional" spatial voting model, over 25 scholarly articles have been devoted to the subject. While some of these papers have sought to articulate the implications of the theory (Merrill 1993) or to generalize it by, for example, explicitly incorporating uncertainty into the model (Macdonald and Rabinowitz 1993b), most debate its empirical merits. Does it work in the United States, France (Pierce 1997), Norway (Macdonald et al. 1991; Westholm 1997), Sweden (Gilljam 1997), Germany (Kramer and Rattinger 1997), or The Netherlands (Macdonald and Rabinowitz 1996a)? Does it explain roll call voting decisions in the U.S. Congress (Platt et al. 1992)? Does it describe all voters or only unsophisticated voters (Macdonald et al. 1995b)?

Beyond its theoretical merits, interest in the directional model has been sustained by the prominence of the alternative against which it has generally been tested. What contributors to the directional voting literature refer to as the "proximity model" has so dominated the research on spatial representations of voter preferences that it is generally referred to as "the spatial theory of voting" (see Hinich and Enelow 1984). The familiar spatial model has a long theoretical and empirical tradition. Well-known results including the Median Voter

Authors' note: Our thanks goes to Jim Alt, Mo Fiorina, Torben Iversen, Stuart Elaine Macdonald, George Rabinowitz, and Anders Westholm for helpful comments, and the National Science Foundation (SBR-9729884), the Centers for Disease Control and Prevention (Division of Diabetes Translation), the World Health Organization, and the National Institute of Aging for research support. 
Theorem of Black (1958) and Hotelling (1929), the McKelvey (1976) Chaos Theorem, Shepsle and Weingast's (1981) Structure-Induced Equilibrium, and Poole and Rosenthal's (1985) Nominate Scores are predicated on the idea that politics can be represented as a Euclidean space (the proximity model) and not an inner product space (the directional model). ${ }^{1}$

The contributors to the literature on directional versus proximity voting are fighting over two central political science issues: our understanding of a basic feature of the political world - how voters make decisions - and a prominent aspect of our data collection strategies-how randomly chosen respondents answer imprecisely worded survey questions. On one hand, we have a group of scholars who have championed directional theory for a decade, and on the other we have a large body of theoretical and empirical rational choice research that rests on the veracity of the proximity model. Despite substantial effort and much thoughtful analysis, the scholarly community does not seem much closer to a resolution. We attempt to explain why this debate persists.

Our purpose is not to declare a winner, or to play Ted Koppel's role on Nightline ("Did you hear what he said about your mother?"), but rather to clarify the complicated issues involved in testing these theories and to lay bare the assumptions one would need to conclude that one side, rather than the other, is correct. Our main argument is that the existing data contain insufficient information with which to distinguish the two theories. The result is that a large and supposedly empirical literature, designed to answer the empirical question of how voters make decisions, too often amounts to data-free debates about which untested assumption is right. More specifically, we demonstrate that (1) in the most general formulation, support for each model is marginal at best; (2) each set of authors is able to produce results that seem to favor their position only by making (and justifying in a variety of interesting theoretical ways) different untested methodological assumptions; and (3) the data are not sufficiently rich to allow an appropriate test that can distinguish between the opposing assumptions employed by each. Despite much hard work, it is still not possible to decide who is right using the kinds of data and methodologies that have been employed in the literature.

For simplicity, our references to the literature draw on the two most recent articles in this debate when possible. That is, we take Westholm (1997) as our exemplar of the defenders of the proximity model and Macdonald, Rabinowitz, and Listhaug (1998) (hereafter MRL) as our exemplar of the defenders of directional theory. Using identical data, the authors find apparently equally strong but opposing support for their favored model.

\section{Definitions}

One way to interpret the common starting point of both theories of voting is by the common assumption that candidates for office can be arrayed on an underlying dimension, such as liberal to conservative. ${ }^{2}$ Figure 1 gives an example with some well-known senators from the 104 th congress. ${ }^{3}$

\footnotetext{
${ }^{1}$ References to many notable empirical tests of the spatial voting model in the context of electoral competition are given by Hinich and Enelow $(1984,1989)$. Countless papers have assumed the spatial model in testing other hypotheses.

${ }^{2}$ In many applications, candidates are ordered in multidimensional space. We use one dimension to clarify the underlying concepts. For expository purposes, here and elsewhere, we use the simplest possible examples and forms of the theories at issue. Both bodies of literature elaborate in many useful ways, but the elaborations do not change the essential points.

${ }^{3}$ We took the exact ideological positions from Poole and Rosenthal (1997) but the same ideas (and, in the case of well-known senators, nearly the same positions) apply regardless of method. The latter is important since Poole and Rosenthal's methods happen to be based on proximity theory.
} 


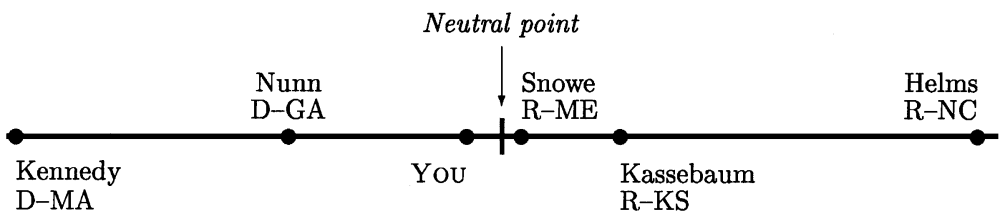

Fig. 1 Senators on an ideological dimension: the dimension ranges from the most liberal at the left to the most conservative at the right. A few senators and "You" are located as filled circles on the dimension. The small vertical bar at the middle represents the neutral point required under directional theory.

Figure 1 is a familiar representation of an ideological issue space, ranging from Edward Kennedy at the most liberal end to Jesse Helms at the most conservative. For illustrative purposes, we have also added "You" to this dimension, with preferences slightly to the left of center.

According to the proximity model, voters prefer candidates closest to them on this dimensional scale. So, according to the model, You would prefer Olympia Snowe as your representative to any of the other senators. Also, the farther away from your position, the less you like the representative. Hence, after Snowe, You prefer Nancy Kassebaum, then Sam Nunn, Edward Kennedy, and, finally, Jesse Helms.

In contrast, under the directional model, voters prefer candidates "on their side," and the more on their side the better. A "side" might be a politically meaningful grouping such as a political party or a like-minded set of people who agree with some basic ideological premises. In the figure, "sides" are determined by your position relative to the neutral point (marked by the vertical line in Fig. 1). Thus, according to the model, You prefer those to the left of zero more than those to the right, because You are on the left. Moreover, You have the strongest intensity of preferences for the extreme candidates on your side because they are most clearly members of your "team." Thus You and everyone else located on the "Liberal" side have the same preference ordering: Kennedy, Nunn, Snowe, Kassabaum, Helms. However "sides" are defined, the position of the neutral point is critical in directional theory (and irrelevant in proximity theory).

MRL exclude from this scheme truly extremist candidates who fall outside of what they call the "region of acceptability" that they use to define mainstream politics. The elected U.S. senators who make up our current example all probably fall within the acceptable region. Thus, under directional theory, voters would penalize more extreme candidates (for example, perhaps, the Right-to-Life Party candidates in New York State or the occasional Communist Party candidate elsewhere).

In some formulations, directional theory describes something closer to the respondent's answer to a survey question than a traditional ideological scale. In that situation, the idea is that people decide only what side they are on and how intense they feel, in which case the underlying ideological dimension in Fig. 1 has a different interpretation than it has in a traditional spatial modeling framework. Indeed, whether respondents use the intermediate values of issues scales to convey their preferences for intermediate policy positions or to reflect the strength of their commitments to one or the other of the positions that anchor the scale is central to this debate. Whether the empirical tests presented below and elsewhere in the literature tell us more about how respondents conceive of Likert scales or how they conceive of politics more generally is of course unclear.

The debate in the literature is focused on whether it is the proximity or directional model that best explains voter behavior. However, implicit in this debate is the simultaneously determined question of what dimension (or dimensions) people use to decide. This makes the question of proximity vs direction conditional on what dimension is being used by voters 
or analyzed by researchers, since it could be the case that people follow the proximity model on some dimensions and the directional model on others. ${ }^{4}$

\section{A Formal Statement of the Models}

In this section we formally define the directional and proximity models of voter decision making. We also introduce a general model that includes both as special cases. This model helps us clarify the theories in this section and the methods and assumptions necessary to produce valid empirical tests, in the next.

Let $v_{i}$ be the numerical position of voter $i$ (for $i=1, \ldots, n$ ) on some issue or ideological dimension like that in Fig. 1 (where the underline points out the mnemonic labeling convention we adopt). Also, let $c_{i j}$ be the ideological position of candidate (or party) $j$ on the same dimension as presented to voter $i$. For this conceptual section, we treat $v_{i}$ and $c_{i j}$ as theoretical quantities that could be measured without error. Even without considering measurement error or psychological concepts such as perception, $c_{i j}$ may in fact vary over $i$ if the candidates present themselves differently to different groups, which is after all the point of many targeted campaign appeals. The neutral point is defined as zero.

While they differ as to how voter utility is defined, both sides agree that utility theory governs actual decision making. So a voter would choose to cast a ballot for candidate 1 over candidate 2 if the voter's utility for 1 is higher than for 2 . What distinguishes the various models of voter decision making is the voter's utility function. Under the directional model, the utility of voter $i$ for candidate $j$ is

$$
U_{i j}^{d}=\alpha^{d}+\beta^{d}\left(v_{i} c_{i j}\right)
$$

where $\alpha^{d}$ and $\beta^{d}(>0)$ are unknown constants. This equation indicates that when a voter and a candidate are on the same side of the neutral point, the voter's utility under the directional model is lowest when the voter or the candidate is near the neutral point (i.e., zero) and highest when both are on the extreme of the same side of the neutral point. The second term is negative if the voter and candidate are on opposite sides and is increasingly negative as the voter or the candidate become more extreme. [We sidestep concerns about the region of acceptability in the analyses below by also running a version of our specifications that drop extremist parties; so for simplicity, Eq. (1) excludes penalties for candidates that fall outside this region, as would otherwise be required by directional theory.]

Under the proximity model, the voter's utility is most commonly written as

$$
\begin{aligned}
U_{i j}^{p} & =\alpha^{p}-\beta^{p}\left(v_{i}-c_{i j}\right)^{2} \\
& =\alpha^{p}-\beta v_{i}^{2}-\beta^{p} c_{i j}^{2}+\beta^{p}\left(2 v_{i} c_{i j}\right)
\end{aligned}
$$

where $\beta^{p}>0$. Eq. (2) defines a voter's maximum expected utility as occurring when the voter and candidate are at the same position. The less proximate the two positions are, the lower the voter's expected utility. ${ }^{5}$

\footnotetext{
${ }^{4}$ Almost all formal theory work assumes the proximity model. Two interesting papers by Merrill (1993, 1995) explore the theoretical consequences for this literature of assuming instead that the directional model applies.

${ }^{5}$ Sometimes the absolute (or "city block") rather than the squared ("Euclidean") distance between $v_{i}$ and $c_{i j}$ is used as a distance measure, but these rarely differ empirically by very much. We choose the squared Euclidean distance because it is more commonly chosen and allows us to nest the directional and proximity models within our "general" model. A similar (though slightly better) fit is achieved using Euclidean distances rather than squared Euclidean distances. Note, also, that $\alpha$ and $\beta$ have different meanings in Eqs. (1) and (2).
} 
Our general encompassing model comes from letting the three $\beta$ 's in the second line of Eq. (2) differ:

$$
U_{i j}^{g}=\alpha-\beta_{v} v_{i}^{2}-\beta_{c} c_{i j}^{2}+\beta_{2}\left(2 v_{i} c_{i j}\right)
$$

The special cases of this general model produce the two behavioral models at issue. The general model equals the directional model (i.e., $U_{i j}^{g}=U_{i j}^{d}$ ) when $\beta_{v}=\beta_{c}=0$ and $\beta_{2}>0$. The general model specializes to the proximity model $\left(U_{i j}^{g}=U_{i j}^{p}\right)$ when $\beta_{v}=\beta_{c}=\beta_{2}>0$. Unlike the directional and proximity models, Eq. (3) is not meant as a theory of voter behavior, only as a device to understand and subsequently evaluate the two behavioral models as special cases. ${ }^{6}$

In the simplest possible case, we have only two parties and one issue. If we had a survey with $n$ interviews, our data set constructed for the analysis would have $2 n$ observations ( $n$ for each party). ${ }^{7}$ The effect of additional issues on utility is assumed here and elsewhere in this literature to be additive. Each additional issue enters the model in the same way as the first and receives its own value of $v_{i}, c_{i j}$, and $\left(2 v_{i} c_{i j}\right)$.

\section{Alternative Assumptions for Empirical Testing}

We now describe three alternative sets of assumptions under which it is possible to estimate the parameters of the model and hence distinguish between the proximity and directional models.

Most applications in this literature measure a voter's utility for a candidate or party with a "feeling thermometer," a survey question resulting in a scale from 0 (feeling "cold" about a candidate) to 50 (the neutral point) to 100 (a "warm" feeling). The voter's position $v_{i}$ and the candidate's position as presented to each voter $c_{i j}$ are measured with 7- or 10-point Likert issue scale questions put to voters. Since the parameters of interest are a linear function of squares and products of variables, they can be estimated by least squares regression.

\subsection{Optimistic Assumptions}

Suppose we were willing to believe that all the methodological problems one might raise were sufficiently minor such that, if ignored, they would not change our conclusions about which theory is correct, or, if corrected, the estimates would be no better. This is a useful starting point in most analyses, especially for understanding the relationships in the data and how imposing alternative assumptions affects these relationships.

In the present case, an optimistic approach to estimation means we could estimate $\alpha, \beta_{v}, \beta_{c}$, and $\beta_{2}$ in Eq. (3) by regressing the feeling thermometer on a constant term, $v_{i}^{2}, c_{i j}^{2}$, and $\left(2 v_{i} c_{i j}\right)$. To provide a feel for the kind of information in the data, we implemented this with the 1989 Norwegian Election Study, ${ }^{8}$ the same data set used by Westholm and MRL

\footnotetext{
${ }^{6}$ Rabinowitz and Macdonald's (1989) so-called "mixed" model is also a special case of our general model, when $\beta_{v}=\beta_{c}$ and $\beta_{2}>0$. Its authors sometimes think of the mixed model as useful for understanding and statistical testing, as we do our encompassing model, but they sometimes also treat it as a model of voter behavior in its own right.

${ }^{7}$ With more than one issue, our general model becomes $U_{i j}^{g}=\alpha-\mathbf{v}_{i}^{\prime} \boldsymbol{\beta}_{\boldsymbol{v}} \mathbf{v}_{i}-\mathbf{c}_{i j}^{\prime} \boldsymbol{\beta}_{\boldsymbol{c}} \mathbf{c}_{i j}+2 \mathbf{v}_{\boldsymbol{i}}^{\prime} \boldsymbol{\beta}_{\mathbf{2}} \mathbf{c}_{i j}$, where $\mathbf{c}$ and $\mathbf{v}$ are now vectors and the $\boldsymbol{\beta}$ 's are now diagonal matrices.

${ }^{8}$ Data distributed by the Norwegian Social Science Data Services (NSD). Bernt Aardal and Henry Valen were the Principal Investigators and the Norwegian Gallup Institute collected the data.
} 
$(N=8833) .{ }^{9}$ (We also replicated the same analyses in U.S. data, which we do not present here; the results are highly consistent with the analyses and conclusions below. ${ }^{10}$ ) We did the estimation for all seven political parties and six issues (a general left-right scale, the environment, agriculture, immigration, health policy, and alcohol restriction). Continuing the notation developed above, denoting the feeling thermometer scores of voter $i$ evaluating candidate $j$ as $T_{i j}$ and indexing each of the issues by $k$, we estimate the following equation by least squares:

$$
T_{i j}=\alpha-\sum_{k=1}^{6} \beta_{v k} v_{i k}^{2}-\sum_{k=1}^{6} \beta_{c k} c_{i j k}^{2}+\sum_{k=1}^{6} \beta_{2 k}\left(2 v_{i k} c_{i j k}\right)+\epsilon_{i j}
$$

With six issues, we have six $\beta_{v}$ 's, $\beta_{c}$ 's and $\beta_{2}$ 's to estimate-one for each corresponding $v_{i}^{2}, c_{i j}^{2}$, and $\left(2 v_{i} c_{i j}\right)$. The results, which appear in Table 1 , indicate that $\beta_{v}$ is usually fairly close to zero, but $\beta_{c}$ and $\beta_{2}$ are both large and positive. ${ }^{11}$ Thus, before correcting any methodological problems, the results do not provide unambiguous support for either the directional model (which requires $\beta_{v}=\beta_{c}=0$ and $\beta_{2}>0$ ) or the proximity model (which requires $\left.\beta_{v}=\beta_{c}=\beta_{2}>0\right)$.

If the results in Table 1 are so mixed, how are Westholm and MRL able to draw such strong and opposing conclusions? The answer depends critically on their differing methodological assumptions and resulting statistical corrections, a subject to which we now turn.

\subsection{Assumptions that Favor Directional Theory}

MRL worry that candidate issue placements, as measured, may be endogenous to the feeling thermometer and thus may be systematically biased. To correct for this problem, MRL ${ }^{12}$ replace each respondent's perception of a candidate issue position $c_{i j}$ with the average issue position in the sample for each party, $c_{j}=\sum_{i=1}^{n} c_{i j} / n$. If the true value of $c_{i j}$ is indeed

\footnotetext{
${ }^{9}$ MRL (1998) argue that Norway's Socialist Left and the Progressive parties are outside of the "region of acceptability" and thus voters will not use directional logic when evaluating them. Instead, these parties suffer some "penalty" for their extreme views. Rather than trying to model the "penalty" directly, we refit all of the models in this paper after excluding these parties. The substantive results given in the text are not altered when these parties are omitted, though the number of issues that can be considered is reduced by two due to an identification problem described below. The number of observations is $n=2198$ respondents $\times 7$ parties missing party-respondent pairs $=8833$.

${ }^{10}$ To be specific, we replicated the analysis with U.S. data using the 1948-1996 NES Cumulative Data File (ICPSR Study No. 8475). In this replication, we used the feeling thermometer scores for all major party presidential candidates from 1972 to 1996 and placements on the liberal-conservative and government guaranteed employment 7-point scales. We choose these two scales because they were included on all NES surveys in the 1972 to 1996 period. As with the Norwegian data, the estimated $\beta_{c}$ 's are similar in magnitude to the $\beta_{2}$ 's, while the $\beta_{v}$ 's are small. Similar results were obtained using the other issue scales included in the data set (equality for women, relations with Russia, minority aid, social services spending, and defense spending) for the subsets of years in which they were asked. Tables and program files for this replication are available in the replication data set that accompanies this article.

${ }^{11}$ The average standard errors given in Table 1 are generated by the usual OLS estimator. One might be concerned that the regression errors are not independent across observations involving the same respondent. If this sort of dependence is present, the OLS standard error estimates are biased and inconsistent. We also employed a Huber sandwich-type estimator that is consistent in the presence of within-respondent dependence. The standard errors estimated in this way were in all cases within \pm 0.01 of the reported standard errors.

${ }^{12} \mathrm{MRL}$ argue that, without this correction, projection effects bias the results toward the Euclidean model. [Projection is the tendency for voters who are uncertain of the parties' issue positions to locate parties they prefer close to their own position (see Brody and Page 1972).] Westholm (1997) argues that it is somewhat inconsistent to assert that voters would locate candidates they prefer close to themselves, but when assuming the directional
} 
Table 1 Estimates of the general model:

Roughly speaking, $\hat{\beta}_{v} \approx 0, \hat{\beta}_{c}>0$, and $\hat{\beta}_{2}>0^{\mathrm{a}}$

\begin{tabular}{lrcc}
\hline Issue & $\hat{\beta}_{v}$ & $\hat{\beta}_{c}$ & $\hat{\beta}_{2}$ \\
\hline Left-right & -0.15 & 0.32 & 0.64 \\
Agriculture & -0.03 & 0.28 & 0.22 \\
Environment & 0.04 & 0.13 & 0.23 \\
Immigration & -0.10 & 0.29 & 0.16 \\
Alcohol & -0.08 & 0.28 & 0.24 \\
Health & 0.04 & -0.23 & 0.23 \\
$\quad$ (Average SE) & $(0.03)$ & $(0.03)$ & $(0.02)$ \\
\hline
\end{tabular}

${ }^{\text {a }}$ For this table, and all that follow, $N=8833$.

constant over $i$, this procedure averages away much of the measurement error and may go some way toward solving the methodological problem. However, if candidates present different ideological positions to different groups of voters (or different voters receive different messages), so that $c_{i j}$ is not constant, the procedure will introduce measurement error. Whether or not $c_{i j}$ is in fact constant over $i$, replacing it with $c_{j}$ has important side effects for estimation.

Table 2 repeats the regression in Table 1 with these mean party placements. The results for this table are qualitatively the same, except that estimates of $\beta_{c}$ are now much less precisely

Table 2 Estimates of the general model with mean party placements: Roughly speaking, $\hat{\beta}_{v} \approx 0$, $\hat{\beta}_{c}>0$, and $\hat{\beta}_{2}>0^{\mathrm{a}}$

\begin{tabular}{lrrc}
\hline Issue & \multicolumn{1}{c}{$\hat{\beta}_{v}$} & $\hat{\beta}_{c}$ & $\hat{\beta}_{2}$ \\
\hline Left-right & 0.02 & -0.46 & 0.90 \\
Agriculture & -0.03 & -0.17 & 0.25 \\
Environment & 0.01 & -0.26 & 0.18 \\
Immigration & 0.02 & 2.78 & 0.35 \\
Alcohol & -0.09 & -0.31 & 0.29 \\
Health & 0.11 & -1.47 & 0.25 \\
$\quad$ Average SE) & $(0.03)$ & $(0.11)$ & $(0.02)$ \\
\hline
\end{tabular}

a Note that compared to the estimates given in Table 1, $\beta_{c}$ is much less precisely estimated.

model, voters would not in general prefer candidates that are in close proximity to themselves. In any event, Merrill and Grofman (1997) demonstrate empirically that the projection effects are modest.

A second reason MRL (1998) give for using mean party location is that each party should be able to take only a single position. Thus, they argue that variation in a party's location across respondents must be attributable to measurement error. Others, such as Enelow and Hinich (1994), argue that this interrespondent variation in party placements is the result mainly of idiosyncratic misperceptions that do bear on voter's utilities. Aldrich and McKelvey (1977) suggest that the individual variation in party placements is attributable largely to interrespondent incomparability in the issue scales (that is, a 3 on one respondent's scale might correspond to a different policy position than a 3 on another respondent's scale). Aldrich and McKelvey develop a clever technique that rescales respondents' placements onto a common metric, an approach that is preferable to the mean placement method and may be a reasonable approach to take in future work. However, since the Aldrich and McKelvey method yields unique party locations, it would also fall prey to the identification problems described in the text. 
Table 3 The MRL approach, mean party placements and fixed effects: Under the general model, candidate fixed effects make $\beta_{c}$ inestimable $^{\mathrm{a}}$

\begin{tabular}{|c|c|c|c|c|c|}
\hline \multirow[b]{2}{*}{ Issue } & \multicolumn{3}{|c|}{ General } & \multirow{2}{*}{$\begin{array}{c}\text { Directional, } \\
\hat{\beta}_{2} \mid\left(\hat{\beta}_{v}=\hat{\beta}_{c}=0\right)\end{array}$} & \multirow{2}{*}{$\begin{array}{c}\text { Proximity, } \\
\hat{\beta}_{2} \mid\left(\hat{\beta}_{v}=\hat{\beta}_{c}=\hat{\beta}_{2}\right)\end{array}$} \\
\hline & $\hat{\beta}_{v}$ & $\hat{\beta}_{c}$ & $\hat{\beta}_{2}$ & & \\
\hline Left-right & 0.02 & $?$ & 0.90 & 0.90 & 0.73 \\
\hline Agriculture & -0.03 & $?$ & 0.25 & 0.26 & 0.14 \\
\hline Environment & 0.01 & $?$ & 0.18 & 0.18 & 0.08 \\
\hline Immigration & 0.02 & $?$ & 0.35 & 0.35 & 0.18 \\
\hline Alcohol & -0.09 & $?$ & 0.29 & 0.29 & 0.16 \\
\hline $\begin{array}{l}\text { Health } \\
\quad \text { (Average SE) }\end{array}$ & $\begin{array}{c}0.11 \\
(0.03)\end{array}$ & $?$ & $\begin{array}{c}0.25 \\
(0.02)\end{array}$ & $\begin{array}{c}0.25 \\
(0.02)\end{array}$ & $\begin{array}{c}0.25 \\
(0.02)\end{array}$ \\
\hline$\hat{\sigma}$ & & 19.87 & & 19.90 & 20.93 \\
\hline$R^{2}$ & & 0.36 & & 0.36 & 0.29 \\
\hline
\end{tabular}

${ }^{a}$ The directional model restrictions fit the data slightly better than the proximity model.

estimated, more variable across issues, and overall less clearly distinguishable from zero. Since $c_{i j}$ was replaced by the statistically less variable and hence less powerful $c_{j}$, this should come as no surprise. Moreover, since party location variables are fixed for each party, as the number of issues increases, the estimates of $\beta_{c}$ are increasingly correlated with any party specific effect on the feeling thermometer that might be omitted from the model (as discussed below), making the estimation of $\beta_{c}$ far more difficult. In fact, the number of parties must exceed the number of issues or $\beta_{c}$ would be inestimable. Nevertheless, with this methodological adjustment, the results now provide somewhat greater support for the directional theory of voting-the restriction that $\beta_{c}=\beta_{v}=0$ is more consistent with the data.

MRL also worry that there might be omitted party-specific attributes that affect feeling thermometer scores, a standard statistical problem. ${ }^{13}$ To correct for these possible omitted party attributes, MRL let $\alpha$ vary over the parties and so estimate $\alpha_{j}$ for all $j$ (a so-called party "fixed-effects" model). Unfortunately, these effects are now perfectly collinear with the squared party positions $c_{j}$ and so $\beta_{c}$ is no longer estimable. ${ }^{14}$ This is indicated by the question marks in the third column in Table 3, where we estimated the general model with mean party placements and fixed effects.

The last two columns in Table 3 specialize our general model under the competing assumptions of the directional and proximity models. The fit statistics indicate that the directional model fits slightly (although "significantly") better than the proximity model. In the directional model, the restriction that $\beta_{v}=0$ has little effect since the unrestricted

\footnotetext{
${ }^{13}$ For example, parties involved in scandal may be given relatively low evaluations by all voters, ceteris paribus. ${ }^{14}$ We can show more intuitively why the party locations are linearly dependent on the set of party fixed effects. That is, one way to formulate the fixed effects model is to transform the data by mean deviating all the variables
} in the data by their within-party means. First, write each observation as

$$
T_{i j}-\bar{T}_{j}=\sum_{k=1}^{6} \beta_{v k}\left(v_{i k}^{2}-\bar{v}_{i k}^{2}\right)+\sum_{k=1}^{6} \beta_{c k}\left(c_{j k}^{2}-c_{j k}^{\overline{2}}\right)+\sum_{k=1}^{6} \beta_{2 k} 2\left(v_{i k} c_{j k}-\overline{v_{i k} c_{j k}}\right)+e-\bar{e}_{j}
$$

where the bars over the variables indicate their within-party means. However, since $c_{j k}^{2}$ does not vary across voters, and $c_{j k}^{2}-c_{j k}^{\overline{2}}=0$ for all parties $j$ and issues $k$, the value of $\beta_{c k}$ will have no effect on the fit of the model. 
estimate in the second column is always approximately zero. Since $\beta_{c}$ is inestimable, the directional model restriction that $\beta_{c}=0$ and the proximity model restriction that $\beta_{c}=\beta_{v}$ have no effect whatsoever. Thus, under this set of methodological assumptions, the proximity model restriction that $\beta_{v}=\beta_{2}$ does have an effect, as it slightly reduces the fit of the model. On this basis, then, MRL conclude that the directional model outperforms the proximity model.

\subsection{Assumptions that Favor Proximity Theory}

Unlike MRL, Westholm and most other defenders of proximity theory are not concerned with problems that might arise from the use of respondents' idiosyncratic party placements. However, Westholm finds other faults with what we have called the standard "optimistic assumptions." Westholm argues that feeling thermometers should not be directly compared across respondents. ${ }^{15}$ The incomparability of utility measures, either observed as in this case or latent as in many choice models, is a serious obstacle to the study of political or consumer choice. Standard utility theory explicitly assumes that any two individuals' utility functions need not be comparable. This incomparability is often unproblematic (though sometimes inconvenient) for developing theoretical results, but for the empirical testing of utility models it is often devastating. Very rarely are we able to observe the same individual in a large number of choice settings. Rather we generally observe only interpersonal, rather than intrapersonal, variation in choice setting. That is, we observe different individuals in different circumstances choosing over the same alternatives. Therefore, we are forced to adopt the dubious "representative consumer" assumption (see Hausman and Wise 1978, pp. 406-407; Kirman 1992). In other words, we treat a set of observations on choices (or, in this case, feeling thermometer ratings) made by different individuals as if they were the choices of a single "average" or "representative" individual.

If we observed only one utility value per respondent, we would have little choice but to treat the feeling thermometer scores as directly comparable across respondents. However, because in the present case multiple feeling thermometer ratings are recorded for each respondent, the feeling thermometer scores need not be treated as directly comparable. Westholm uses this panel-like structure of the data to relax the representative consumer assumption. By allowing $\alpha$ to vary by respondent, Westholm's method effectively treats differences in, and not levels of, feeling thermometers as comparable across respondents. ${ }^{16}$ As is often the case, the relaxation of an assumption comes at a cost. ${ }^{17}$ Specifically, by assuming that feeling thermometer scores are strictly comparable across repeated measurements within and across individuals for levels and differences, MRL are able to test implications of the proximity model such as "A voter should be indifferent between being

\footnotetext{
${ }^{15}$ In the simplest case, this would mean that the $\alpha$ 's and $\beta$ 's vary across respondents. More generally, any monotonic transformation of utility (in this case, as measured by a feeling thermometer) represents the same preferences. Brady (1989) considers the problem of interpersonal comparability of feeling thermometer scores in the context of the traditional spatial model. Brady's model treats the feeling thermometers as ordinal measures. Transforming the feeling thermometer scores to ranks and applying econometric techniques appropriate for ranked data is a potentially promising line of future research in the directional voting literature. However, such methods would, like Westholm's method, leave $\beta_{v}$ unidentified.

${ }^{16}$ Variation in the $\alpha$ 's could be introduced by the inclusion of random rather than fixed effects. However, this would require an ex ante assumption to be made about the correlation between the random effects and the independent variables. The usual assumption is that the effects are independent of the regressors. Using a Hausman-type test, we can reject $\left(\chi^{2}(12)=115.7\right)$ the notion of independent random effects in these data (conditional on either the directional or proximity model).

${ }^{17}$ It should be noted that Westholm's method does in fact require the comparison of differences in feeling thermometer scores across respondents. His analysis is not based solely on intrarespondent utility.
} 
Table 4 The Westholm approach, voter fixed effects: Under the general model, voter fixed effects make $\beta_{v}$ inestimable ${ }^{\mathrm{a}}$

\begin{tabular}{lccccc}
\hline & \multicolumn{3}{c}{ General } & & $\begin{array}{c}\text { Directional, } \\
\text { Issue }\end{array}$ \\
\cline { 2 - 4 } & $\hat{\beta}_{v}$ & $\hat{\beta}_{c}$ & $\hat{\beta}_{2}$ & $\hat{\beta}_{2} \mid\left(\hat{\beta}_{v}=\hat{\beta}_{c}=0\right)$ & $\begin{array}{c}\text { Proximity, } \\
\hat{\beta}_{2} \mid\left(\hat{\beta}_{v}=\hat{\beta}_{c}=\hat{\beta}_{2}\right)\end{array}$ \\
\hline Left-right & $?$ & 0.37 & 0.61 & 0.60 & 0.53 \\
Agriculture & $?$ & 0.32 & 0.22 & 0.29 & 0.22 \\
Environment & $?$ & 0.17 & 0.23 & 0.31 & 0.20 \\
Immigration & $?$ & 0.24 & 0.18 & 0.14 & 0.18 \\
Alcohol & $?$ & 0.35 & 0.25 & 0.26 & 0.26 \\
Health & $?$ & -0.21 & 0.25 & 0.27 & 0.21 \\
$\quad$ Average SE) & & $(0.04)$ & $(0.02)$ & $(0.02)$ & $(0.02)$ \\
\multicolumn{1}{c}{$\hat{\sigma}$} & & 18.15 & & 19.08 & 18.57 \\
$R^{2}$ & & 0.50 & & 0.43 & 0.47 \\
\hline
\end{tabular}

a The proximity model restrictions fit the data slightly better than than the directional model.

a strong conservative with Barry Goldwater as president and being a strong liberal with Lyndon Johnson as president." This prediction is somewhat forced since people normally cannot "choose" to be liberals or conservatives in the same way that they can choose to support Johnson or Goldwater, but nothing in choice theory prevents individuals from having preferences over outcomes they cannot achieve. Just as one might prefer to have been born healthy, wealthy, and wise, one can also prefer to be a liberal in Sweden or a conservative in Utah.

Since voter issue positions are fixed across candidates in his model, and he rules out direct comparison of two voters' evaluations of the same candidate, Westholm's relaxation of the strong incomparability assumption removes the restriction placed on $\beta_{v}{ }^{18}$ Since the estimates of $\beta_{v}$ in our general model are near-zero, and the proximity model previously required $\beta_{v}=\beta_{c}=\beta_{2}$, removing the restriction on $\beta_{v}$ greatly increases the empirical fit of the proximity model while making it harder to distinguish it from the directional model.

To rule out direct comparisons of the utility levels across voters while still allowing utility differences to be comparable, Westholm includes voter "fixed effects." This involves estimating a separate $\alpha_{i}$ for each voter (which is equivalent to including a dummy variable for each voter). Since $v_{i}^{2}$ is fixed over $i, \alpha_{i}$ and $\beta_{v}$ (the coefficient on $v_{i}^{2}$ ) are not separately identified. (For example, the estimate of $\beta_{v}$ could be doubled without changing voters' predicted feeling thermometer scores for any candidate simply by subtracting $\beta_{v} v_{i}^{2} / 2$ from each of the previously estimated $\alpha_{i}$ ).

Table 4 provides estimates under Westholm's assumptions. In our general model, $\beta_{v}$ is inestimable and hence represented by question marks. Respondent fixed effects have little

\footnotetext{
${ }^{18}$ Because the inclusion of voter fixed effects is equivalent to mean-deviating the data by within-voter means, and because voter positions $v_{i k}$ are fixed across parties, we encounter the same identification problem for $\beta_{v}$ that we described above for $\beta_{c}$ with included party fixed effects. Using the mean-deviated forms and letting the bars over the variables represent within-voter means, we would have
}

$$
T_{i j}-\bar{T}_{j}=\sum_{k=1}^{6} \beta_{v k}\left(v_{i k}^{2}-\overline{v_{i k}^{2}}\right)+\sum_{k=1}^{6} \beta_{c k}\left(c_{j k}^{2}-\overline{c_{j k}^{2}}\right)+\sum_{k=1}^{6} \beta_{2 k} 2\left(v_{i k} c_{j k}-\overline{v_{i k} c_{j k}}\right)+e-\bar{e}_{j}
$$

Because $v_{i k}$ is fixed for each voter $i, v_{i k}-\bar{v}_{i k}=0$ for all voters $i$ and $\beta_{v}$ is not identified. 
effect on estimates of $\beta_{c}$ (compare column 3 in Tables 4 and 1). Since it is not identified, the different restrictions on $\beta_{v}$ under the directional and proximity models have no effect on estimation. However, since unrestricted estimates from the general model of $\beta_{c}$ and $\beta_{2}$ are both large, the restriction under the proximity model $\left(\beta_{c}=\beta_{2}\right)$ outperforms the restrictions under the directional model $\left(\beta_{c}=0\right)$, as indicated by the fit statistics in the last two columns.

\section{Concluding Suggestions}

Do voters decide based on proximity or direction? Like all inferences, any decision requires making some untestable assumptions. In this case, the alternative possible methods used to relax the most questionable of these assumptions are far from innocuous. Which assumptions we choose to relax depends on which seem more important. Westholm and MRL make very strong, and diametrically opposed, cases for relaxing different assumptions. They are both right to a degree, in that each of the methodological problems raised could seriously bias the results if left untreated. However, the data available are insufficient to relax all the assumptions at issue in a single model. It is unfortunate that the scholarly community is left with theoretical analyses for deciding these empirical questions, but until survey researchers or experimentalists produce better measurement devices, or political methodologists generate better methodological approaches, the impass will remain. We now offer some suggestions for future researchers looking for ways to put this debate on empirically solid microfoundations.

1. It may be possible to design a survey experiment where $v_{i}$ and $c_{i j}$ are manipulated exogenously without error so that Eq. (3) is estimable without assumptions. This would seem to be an important component of any satisfactory solution, since if we cannot design an experiment-even in principle - to answer the critical questions at hand, there is little hope of making inferences from observational data.

2. Scholars could work to demonstrate precisely how feeling thermometer scales are predicted by demographic variables. This may undermine Westholm's claim that they are interpersonally incomparable.

3. Work by Grofman et al. on "projection bias" might be extended, which might be seen as undermining MRL's assumptions.

4. It would be very helpful to extend studies that use intensive interviews or "debriefings" with survey respondents to study precisely how people think about, explain, and understand our survey questions (e.g., Kaiser 1984). This kind of work is typically done when pretesting survey instruments, but feeling thermometers and the various issue questions were never designed to test directional and proximity theories.

5. Much of the debate surrounding directional versus proximity voting comes down to disagreements about the appropriateness of various additions to the basic parametric model or to the parameterization itself. For example, some have wondered if, in the operationalized proximity model, the feeling thermometer should be proportional to a Euclidean distance or "city block" metric, rather than to a squared Euclidean distance as we (and most others) have assumed. Thus, another fruitful approach may be to test these theories semi- or nonparametrically (e.g., Pierce 1993). One such approach we have explored is to model a person's feeling thermometer answers on a set of questions as ordinal rankings (e.g., Bloom and Cavanagh 1986). This type of model entails some interesting statistical issues that we hope to pursue in future research. 
The body of literature attempting to distinguish proximity vs directional voting has been growing fast. Yet in our view, this scholarship has been confined to a relatively narrow methodological tradition, and scholars have analyzed only a few types of data sets. Unfortunately, there exists essentially no evidence within this tradition and these data to distinguish between the two models. Perhaps as a consequence, other scholars have probably paid insufficient attention to this controversy. However, the issue is clearly critical, as it potentially threatens to undermine a large fraction of the work on formal rational choice and empirical voting behavior. That there exists no evidence for one of the most elementary assumptions underlying work in these fields is worthy of much future attention. We hope that our research leads future researchers to pursue these important questions more productively.

\section{References}

Aarts, Kees, Stuart Elaine Macdonald, and George Rabinowitz. 1996a. "Issue Competition in the Netherlands." Presented at the European Consortium for Political Research Joint Sessions of Workshops, Oslo, Norway.

Aarts, Kees, Stuart Elaine Macdonald, and George Rabinowitz. 1996b. "Issue Competition and Party Support in the Netherlands." Presented at the Annual Meetings of the Political Science Association, San Francisco, CA.

Aldrich, John H., and Richard D. McKelvey. 1977. "A Method of Scaling with Application to the 1968 and 1972 Presidential Elections.” American Political Science Review 71(1):111-130.

Black, Duncan. 1958. Theory of Committees and Elections. Cambridge: Cambridge Univerisity Press.

Bloom, David E., and Christopher L. Cavanagh. 1986. "An Analysis of the Selection of Arbitrators.” The American Economic Review 76(3):408-422.

Brady, Henry. 1989. "Factor and Ideal Pont Analysis for Interpersonally Incomparable Data." Psychometrika 54(2):181-202.

Brody, Richard A., and Benjamin J. Page. 1972. "Comment: The Assessment of Policy Voting." American Political Science Review 66(2):450-458.

Dow, Jay. 1998. "Directional and Proximity Models of Voter Choice in Recent U.S. Presidential Elections." Public Choice 96:259-270.

Downs, Anthony. 1957. An Economic Theory of Democracy. New York: Harper \& Row.

Enelow, James M. 1989. "The Location of American Presidential Candidates: An Empirical Test of a New Spatial Model of Elections." Mathematical Computational Modeling 12:461-470.

Enelow, James M., and Melvin J. Hinich. 1994. "A Test of the Predictive Dimensions Model in Spatial Voting Theory.” Public Choice 78:155-169.

Gilljam, Mikeal. 1997. "The Directional Theory Under the Magnifying Glass: A Reappraisal.” Journal of Theoretical Politics 9:5-12.

Hausman, Jerry A., and David A. Wise. 1978. "A Conditional Probit Model for Qualitative Choice: Discrete Decisions Recognizing Interdependence and Heterogeneous Preferences." Econometrica 46(2):403-426.

Hinich, Melvin J., and James M. Enelow. 1984. "The Spatial Theory of Voting: An Introduction.” Cambridge: Cambridge Univerisity Press, 1984.

Hinich, Melvin J., and James M. Enelow. 1989. "The Location of American Presidential Candidates: An Empirical Test of a New Spatial Model of Elections." Mathmatical Computer Modelling 12(4):461-470.

Hotelling, Harold. "Stability in Competition.” Economic Journal 39(March):41-57.

Iversen, Torben. 1994a. "The Logics of Electoral Politics: Spatial, Directional, and Mobilization Effects." Comparative Political Studies. 27:196-210.

Iversen, Torben. 1994b. "Political Leadership and Representation in Western European Democracies: A Test of the Three Models of Voting." American Journal of Political Science 38:46-74.

Kaiser, Diane Sue. 1984. A Critique of Voting Behavior Research as a Form of Explanation. Ph.D. dissertation. Madison: University of Wisconsin.

Kirman, Alan P. 1992. "Whom or What Does the Representative Individual Represent." Journal of Economic Perspectives 6(2):117-136.

Kramer, Jorgen, and Hans Rattinger. 1997. "The Proximity and the Directional Theories of Issue Voting: Comparative Results for the U.S. and Germany." European Journal of Political Science 32:1-29.

Listhaug, Ola, Stuart Elaine Macdonald, and George Rabinowitz. 1990. "A Comparative Spatial Analysis of European Party Systems.” Scandinavian Political Studies 13:327-354. 
Listhaug, Ola, Stuart Elaine Macdonald, and George Rabinowitz. 1991. "The Role of Issues in Elections: Voting Decisions in Norway and the United States." Presented at the Annual Meetings of the American Political Science Association, Washington, DC.

Listhaug, Ola, Stuart Elaine Macdonald, and George Rabinowitz. 1994. "Ideology and Political Support in Comparative Perspective.” European Journal of Political Science 25:111-149.

Macdonald, Stuart Elaine, and George Rabinowitz. 1993a. "Direction and Uncertainty in a Model of Issue Voting." Journal of Theoretical Politics 5:61-87.

Macdonald, Stuart Elaine, and George Rabinowitz. 1993b. "Ideology and Candidate Evaluation." Public Choice 76:59-78.

Macdonald, Stuart Elaine, Ola Listhaug, and George Rabinowitz. 1991. "Issues and Party Support in Multiparty Systems." American Journal of Political Science 85:1107-1131.

Macdonald, Stuart Elaine, George Rabinowitz, and Ola Listhaug. 1995a. "Issue Competition and Multiparty Politics: Insights from the 1993 Norwegian National Election." Presented at the Annual Meetings of the American Political Science Association, Chicago, IL.

Macdonald, Stuart Elaine, George Rabinowitz, and Ola Listhaug. 1995b. "Political Sophistication and Models of Issue Voting." British Journal of Political Science 25:453-483.

Macdonald, Stuart Elaine, George Rabinowitz, and Ola Listhaug. 1998. "On Attempting to Rehabilitate the Proximity Model: Sometimes the Patient Just Can't be Helped.” Journal of Politics 60:653-690.

McKelvey, Richard D. 1976. "Intransitivities in Multidimensional Voting Models and Some Implications for Agenda Control.” Journal of Economic Theory 12:472-482.

Merrill, Samuel. 1992. "An Empirical Test of the Proximity and Directional Models of Spatial Competition: Voting in Norway and Sweden." Presented at the First Meeting of the of Society for Social Choice and Welfare, Caen, France.

Merrill, Samuel. 1993. "Voting Behavior Under the Directional Spatial Model of Electoral Competition.” Public Choice 77:739-756.

Merrill, Samuel. 1995. "Discriminating Between the Direction and Proximity Spatial Model of Electoral Competition.” Electoral Studies 14:273-287.

Merrill, Samuel, and Bernard Grofman. 1997. "Directional and Proximity Models of Voter Utility and Choice: A New Synthesis and an Illustrative Test of Competing Models.” Journal of Theoretical Politics. 9:25-48.

Merrill, Samuel, Bernard Grofman, and Scott Feld. 1996. "Nash Equilibrium Strategies in Directional Models of Two-Candidate Spatial Competition." Presented at the Annual Meeting of the Public Choice Society, Houston TX.

Pierce, Roy. 1993. "Directional Versus Proximity: A Second Opinion.” Presented at the Annual Meetings of the American Political Science Association, Washington, DC.

Pierce, Roy. 1995. "Directional Versus Proximity Models of Voter-Candidate Issue Linkages in France and the United States,” Typescript. Ann Arbor: Center for Political Studies, University of Michigan.

Pierce, Roy. 1997. "Directional Versus Proximity Models: Verisimilitude as the Criterion." Journal of Theoretical Politics. 9(January):61-74.

Platt, Glenn, Keith T. Poole, and Howard Rosenthal. 1992. "Directional and Euclidean Theories of Voting Behavior: A Legislative Comparison.” Legislative Studies Quarterly 17:561-572.

Poole, Keith T., and Howard Rosenthal. 1985. "A Spatial Model for Legislative Roll-Call Analysis." American Journal of Political Science 29(2):373-399.

Rabinowitz, George, and Stuart Elaine Macdonald. 1989. "A Directional Theory of Voting." American Political Science Review 83:93-121.

Rabinowitz, George, Stuart Elaine Macdonald, and Ola Listhaug. 1991. "New Player in an Old Game: Party Strategy in Multiparty Systems." Comparative Political Studies 4:147-185.

Rabinowitz, George, Stuart Elaine Macdonald, and Ola Listhaug. 1993. "Competing Theories of Issue Voting: Is Discounting the Explanation?" Presented at the Annual Meetings of the Political Science Association, Chicago, IL.

Shaffer, William. 1994. "A Congruence Model of Issue Voting." Presented at the Annual Meetings of the American Political Science Association, Chicago, IL.

Shepsle, Kenneth, and Barry Weingast. 1981. "Structure-Induced Equilibrium and Legislative Choice." Public Choice 37:503-519.

Westholm, Anders. 1997. "Distance Versus Direction: The Illusory Defeat of the Proximity Theory of Electoral Choice.” American Political Science Review 91(4):865-885. 